\title{
Discussion on the Computer Network Course Teaching Model Based on the Concept of MOOC
}

\author{
Wang Weiqiang ${ }^{1, a}$ \\ ${ }^{1}$ Chongqing College of Electronic Engineering, China \\ awwq0109@126.com
}

Keywords: Computer Network Course, Teaching Model, MOOC

Abstract. In this paper, we took the computer network curriculum for example, analysis the problems the course currently facing. And this paper also discussed computer network teaching course based on MOOC mode: teaching content, instructional design, teaching methods, experimental set-up, operation and curriculum assessment.

\section{Introduction}

From the development of the network, the nature of the Internet is to promote information communication society, so society to exchange information and to obtain higher efficiency and lower cost. Online education is undoubtedly very consistent with the law, in the case of all things are interconnected, so much online education market via the Internet, will no doubt achieve a greater leap. Large open online course (Massive Open Online Courses, MOOC, namely Mu class) is a large-scale learner, learner by way of the Internet network classroom learning. Computer Network Computer and related professional courses as a very important basic course, has a very important role in the curriculum architecture. Ways and means of computer network curriculum teaching determines the students' interest and expertise to master the intensity. With the popularity of MOOC way, the traditional teaching model for its inherent limitations urgent need to make the appropriate changes in order to adapt to the teaching requirements of the new era [1].

\section{The Features of MOOC Teaching}

MOOC way of teaching based on the nature of the way online learning is also based on the network, but with the traditional network teaching and essentially different, mainly reflected in the design of teaching methods and instructional design principles connecting doctrine they follow [2].

The Teaching Design of the MOOC. MOOC teaching design approach has changed the classroom teacher as the main identity and it reflects the students as the main role of the teacher as a guide instructional design, mainly for the following ways:

The use of fine-grained knowledge designed to explain individual knowledge is usually controlled in about 5-10 minutes, so that students in the learning process to maximize effective learning time.

Use the Internet model to handle interaction with students, in response to student concerns, mainly by way of panel discussions handle interaction with students.

Objectively use exercises and quizzes online exam online evaluation system for the purpose of scientific and rational way students learn curriculum assessment.

The Instructional Design of Build Approach. The use of instructional design build approach MOOC can easily collect, handle all types of information resources, information is then assembled into a resource classification related topics, in order to facilitate the classification of different types of students to learn.

Web-based teaching methods MOOC break the traditional teaching materials immobilized mode, you can not change the curriculum system in case of a combination of different materials cropped.

By way of the Internet for communication and other instructional designers, in order to further enhance the effectiveness of instructional design. 


\section{The Challenges Facing the Computer Network Curriculum Teaching}

With advances in computer technology, the introduction of computers into the teaching activities in the form of multimedia teaching has changed the traditional teaching activities "blackboard + chalk" teaching mode, but ordinary multimedia teaching methods at this stage still faces enormous challenges, mainly in the following aspects.

Teaching Content Selection Is Limited. Integrated part of domestic and foreign computer network classic textbook, Professor Tanenbaum's Computer Network and Professor Xie Xiren "computer network" are to organize content by five OSI seven-layer model to simplify the model after the course content from the physical layer to the application layer gradually explain the basic concepts of the network, basic principles, related technologies and applications, which is characterized by the concept of clear, clear hierarchy, but the content of emphasis on theory, not easy to use experimental verification of the theory. Edited by Professor Kurose Computer Networks: A Top-Down Approach Featuring the Internet places Internet as the main clue, from the physical layer to the application layer gradually explain the principles of computer network protocol, the textbook designed a lot of after-school practice tasks, so that students in practice to master the network works, but requires students to be able to practice after school to complete these tasks independently conscious. Professor Peterson editor of Computer Networks: A Systems Approach same bottom-up layer by layer to explain the idea, Professor Peterson opposition to strict hierarchical computer network, computer network more emphasis on overall system concept, the textbook content more abundant, the need for adequate the number of hours in order to achieve better learning outcomes. But no matter what type of materials they contain content are limited, it is difficult to do both at the same time to explore the principles of classic and cutting-edge research in the field of in-depth inquiry. And in the selection of multimedia teaching content harder to achieve the appropriate balance, subject to the class, the teacher usually only explain the OSI seven-layer model to five after the simplified model, advanced topics, such as the Internet network measurement, software-defined networking (SDN) and so difficult to relate, but was unable to involve the frontiers of knowledge networks [3].

Instructional Design Diversity Is Inadequate. Although universal expansion of multimedia teaching has enhanced the teaching design concept in large part, but with the advances in network technology, its limitations also began to be reflected. Multimedia in teaching design, although many can be introduced, such as video and other material, but on the whole still is to explain the main teaching, teachers in teaching activities of the dominant position of the students in a passive acceptance of knowledge, and long is too long when the current classroom teaching, Students cannot always maintain a strong concentration, and thus the students 'interest in learning the curriculum also become weak, which is very detrimental to master students' knowledge. Multimedia stage of subject teaching time and assessment methods, it is difficult to introduce such as class discussion, group activities and games, instructional design, instructional design or intentional introduction of teachers and other classroom discussion in the classroom, can only go beyond that cannot really allow students to become the main body of learning.

Laboratory Facilities are Limited. Multimedia teaching computer network courses taught at this stage of the theoretical and experimental aspects were, for some validation experiments, after the completion of the theoretical lectures, students do not necessarily understand the principle, but need to be verified immediately in order to strengthen their knowledge mastery. Subject to a physical computer network equipment prices and experimental teaching space and other factors, to build application-oriented university computer network hardware test environment less, which is not enough to equip students with theoretical knowledge in the experiment session, so this situation an urgent need to make the appropriate change.

The Assessment Methods Are Unreasonable. Computer network course assessment methods are usually adopted final exam and usually integrated computing performance, the level of understanding of the final exam usually only assess students theory, can only reflect in-depth understanding of the course the students in some extent, but to fully grasp the extent of student learning curriculum, assessment system must be appropriate for such changes[4]. 


\section{The Computer Network Teaching Based on MOOC}

Said computer network for the challenges facing the teaching curriculum, this paper will combine the advantages of teaching MOOC from six teaching content, instructional design, teaching methods, experimental set-up, operation, curriculum assessment and other computer network curriculum teaching mode to explore MOOC .

Teaching Content. MOOC-based approach, teaching content cannot increase the burden on students, the integrated computer network of the classic textbook, textbook classic tailoring restructuring and enrich the teaching content, to achieve both breadth and depth. Thanks to the network MOOC teaching methods, can be categorized lists a number of after-school reading materials for students to read, so that students have the ability to understand the materials on the basis of further deepening the understanding of the course. At the same time, it can also increase on the basis of materials on the forefront of research for students in the art of selective research, such as on the basis of a wireless network can be increased networking, VANET other cutting-edge technologies, and thus broaden their horizons and improve students' interest in learning computer network.

Instructional Design. MOOC-based approach, instructional design approach can be flexible, the introduction of participatory teaching methods in teaching classroom discussions, brainstorming, role play, group activities, games, case studies, and further build student-centered, teacher-guided by teaching system design. MOOC network classroom teaching mode, in order to stimulate students' thinking breadth can be set to discuss related issues, and this discussion could even learn a spontaneous group behavior, without the constraints of teachers. To give students a better understanding of the development process and other existing computer and network technology, you can set the appropriate module to demonstrate technical review and forecast future technologies IBM, Cisco, Microsoft, Huawei and other companies to like, so you can open up students career, while allowing them to better understand the current situation and the future of computers and networks, to stimulate their interest in learning computer network. Based on many years of observation of the students, most computer class students' online games have more interest. MOOC classroom mode in the network can be easily introduced into such Cisco Aspire, a network engineer at Cisco's role-playing game, so that students master in the game to further promote the application of knowledge. Computer network course eventually need to be practical application in real life, so set the appropriate case analysis may be disposed on the fine-grained knowledge about the process.

Experimental Setup. In the network technology of study, subject to the restrictions of network equipment price and location, but also limited by the complexity of network structures, modern computer network technology learning is often carried out in a simulation environment. MOOC manner according to the characteristics of network teaching, the use of NS3, Matlab, Packet Tracer simulation software to build a virtual laboratory, etc., so that students in practice is no longer limited to the physical laboratory restrictions on the more abstract theoretical learning process utilizing test positive verify, to deepen the knowledge of control efforts.

Job Training Settings. MOOC-based approach, instructional design knowledge network designed to fine-grained, generally requires that each knowledge point are 5 to 10 minutes, so the job is usually in the knowledge-based multiple choice, and the title should not be too many. Also, when setting up a job in the knowledge required practice various aspects into account, not only to equip students with knowledge, respect knowledge can start to imagine, not too complicated.

Course Assessment. Network-based teaching conditions MOOC way, the assessment in the usual sense of the course is based network, so the need to assess all aspects of the way for change. Overall, the evaluation results need to reflect: Workbook (1) group discussion and knowledge points in the final assessment also occupies a very important role, students must abandon the past to rely solely on the final exam will be able to play to get a good Thought examination results, which students more fair appraisal; (2) to develop a more rigorous and rational assessment rules, but also to students with humane considerations, such as allowing students to study topics of interest to increase to offset the part of the job training and so on [5]. 
Teaching Method. Network-based teaching conditions MOOC way theoretically unlimited number of hours, so you can more easily integrated use of case type, a variety of teaching methods of inquiry, problem type, etc. Concept of online teaching highlight the dominant position of student learning, changing the teaching activities of dominance in the late teacher teaching process more play guide, and discuss the role of supervisor. But it is worth noting that the way of teaching knowledge MOOC are fine-grained, instructors need to quickly grab when you explain the excitement when the students in order to improve students' interest in learning knowledge points. MOOC way of teaching methods based on the instructor requirements are higher, not only instructors the larger balance of knowledge smaller and more clearly explained in the limited time together but also have a certain depth , exercises in the knowledge points and thematic reading material and so need to be focused, moderate difficulty.

\section{Conclusions}

While MOOC-based web teaching methods can better promote students 'professional learning ability, but still need to pay attention to the problems and improve teachers' teaching level under based on MOOC, guide students learning a reasonably, urging students to maintain the continuity of learning and improve education teaching methods in practice, explore and improve the integration of traditional teaching and MOOC-based network teaching way to achieve the purposes of the promotion of student learning professional knowledge and improvement of self-learning ability.

\section{References}

[1] Robinson A: Journal of Geography in Higher Education, Vol. 1 (2015) No 53, p.25-26

[2] Pappano L: The New York Times, Vol. 12 (2005) No 27, p.74-76

[3] Al-Atabi M: Electronic Educational Research, Vol. 1 (2006) No 14, p.11-14

[4] Nanzhong Wu: Electronic Educational Research, Vol. 3 (2015) No33, p.121-124

[5] Qin Guo: Computer and Network, Vol. 1 (2012) No 25, p.88-93 